\title{
Correction to: Extra-esophageal Manifestations of Pediatric Gastroesophageal Reflux Disease: Updated Review
}

Zeyad M. Abdulkader, $M D^{1,{ }^{*}} \odot$

Frederick Woodley, $P h D^{1}$

Peter L. Lu, MD, MS ${ }^{1}$

\section{Address}

*,1Department of Pediatric Gastroenterology, Nationwide Children's Hospital, 700 Children's Drive, Columbus, $\mathrm{OH}$ 43205, USA

Email: zeyad.abdulkader@nationwidechildrens.org

Published online: 20 January 2022

๑ Springer Nature Switzerland AG 2022

The original article can be found online at https://doi.org/10.1007/s40746-021-00229-4.

Correction to: Current Treatment Options in Pediatrics (2021) 7:217-228

$$
\text { https://doi.org/10.1007/s40746-021-00229-4 }
$$

The article "Extra-esophageal Manifestations of Pediatric Gastroesophageal Reflux Disease: Updated Review", written by Abdulkader, Z.M., Woodley, F., and Lu, P.L., was originally published electronically on the publisher's internet portal on 18 November 2021 with error on the second author name. 'Frederick Woodley' was incorrectly written as 'Fredrick Woodley'.

The original article has been corrected.

\section{Publisher's Note}

Springer Nature remains neutral with regard to jurisdictional claims in published maps and institutional affiliations. 